\title{
Kinetic of Phenol Adsorption by Mesoporous MCM-41 Nanoparticles
}

\author{
Dhananjay Naidu, Pallabi Pattanaik, Anup Anang Das, Naresh Kumar Sahoo
}

\begin{abstract}
In the present study application of MCM-41 for removal of phenol was investigated. MCM-41nano-adsorbent was synthesized and characterized by FTIR, XRD and SEM analysis. Adsorption isotherm experiment was performed in batch shake flask. The experimental data were analyzed using various isotherm models. Result revealsthat,Langmuir isotherm model fitted the data very well for the removal of phenol by the MCM-41 adsorbents. The calculated dimensionless separation factor, $R L$ indicates that the adsorption of phenol onto MCM-41 was favorable. Pseudo-first order, pseudo-second order kinetic equations and intraparticle diffusion model were applied to analyze the adsorption kinetics of the MCM-41 at different initial phenol concentrations. It was found that the adsorption of phenol on to the MCM-41 follows the pseudo-second order kinetic. At an initial phenol concentration of $130 \mathrm{mgl}-1$, more than $99 \%$ phenol, 93\% COD along with $96 \%$ of toxicity removal were achieved. Thus, the synthesized mesoporous MCM-41 proved to be a potential candidate for removal of phenol from industrial wastewater.
\end{abstract}

Keywords.Adsorption; MCM-41; phenol; adsorption kinetics; intraparticle diffusion model; toxicity removal.

\section{INTRODUCTION}

The rapid growth and development of industrial sectors is the major concern in the globe, whichreleases anenormous quantity of toxic phenolic pollutants to the receiving environment. In general phenolic wastewater are releases from different industries such as; iron and steel plant, phenolic resin, pharmaceutical,petroleum refineries, wood preservative and pesticides[1-3]. Sometimes these pollutants leachfrom soil and surface water consequently contaminates groundwater [4]. The phenolic pollutants are known to be carcinogenic and teratogenic in nature. The permissible limit of these phenolic pollutants is fixed at $1 \mu \mathrm{gl}-1$ [5]. Therefore, thesepollutants oughtto be removed before being released in to the environment.

Several techniques have been investigated for the removal of phenolic compounds from different synthetic and real industrial wastewater such as; bioremediation, advanced oxidation, electrochemical process and physico-chemical

Revised Manuscript Received on September 14, 2019.

Dhananjay Naidu, Department of Chemistry, Environmental Science and Technology Program, Institute of Technical Education and Research, Siksha'O'Anusandhan, (Deemed to be University), Bhubaneswar, Odisha, India.

Pallabi Pattanaik, Department of Chemistry, Environmental Science and Technology Program, Institute of Technical Education and Research, Siksha'O'Anusandhan, (Deemed to be University), Bhubaneswar, Odisha, India.

Anup Anang Das, Department of Chemistry, Environmental Science and Technology Program, Institute of Technical Education and Research, Siksha'O'Anusandhan, (Deemed to be University), Bhubaneswar, Odisha, India.

Naresh Kumar Sahoo, Correspondence Author, Department of Chemistry, Environmental Science and Technology Program, Institute of Technical Education and Research, Siksha'O'Anusandhan, (Deemed to be University), Bhubaneswar, Odisha, India. (Email: nareshsahoo@soa.ac.in) separation. Among them,removal of pollutants using adsorptionmethod is very promising and popular. Several adsorbents,for instance; activated carbon, clay andfly ashes have been extensively studied for phenol removal[6]. The mesoporousMCM-41is a promising adsorbent which offers high surface area, numerous cylindrical pore structureswith large pore volume [7,8]. Several toxic pollutants like chromium, lead and mercury etc are efficiently removed by mesoporous MCM-41 as adsorbent [9]. Though removal of different toxic compounds by adsorptionmethods is very popular however, phenolic compounds removal by MCM-41 not yet studied extensively so far.

In the present study, MCM-41 nanoparticle was synthesized, characterizedand its kinetic of phenol adsorption was evaluated to increase the phenolic and efficiency of toxicity removal from contaminated wastewater. MCM-41 is a part of the mesoporous silicate family known as M41S. Metal silicate materials applied as molecular sieves have a wide range of (13-100A) pores in hexagonal order. All such items are formulated by a liquidtool crystal-templating system, which is then removed by calcination or acid dissolution from the organic template. The properties are characterized by organized ranges of preservative templates, and by changing the length of the surfactant's hydrocarbon chain, the pores are adjusted. Various surfactant/si relationships and molecular circumstances generate solids with standardized cylindrical pores in hexagonally ordered order (MCM-41), coating materials(MCM-50), three-dimensional pores as well as suggested Cuba Symmetry(MCM-48). Such components may be helpful for catalytic, electronic, optical, and magnetic purposes. Changes by functional molecules can lead to adsorbents of certain characteristics.

\section{EXPERIMENTAL}

\subsection{Materials}

In the present investigation, analytical and laboratory grade of chemicals were employed. Particularly, cetyltrimethylammonium bromide (CTAB), Tetraethylortho silicate (TEOS), as well as other chemicals used ware purchased from Sigma Aldrich, Hi-Media India and Merck India.

\subsection{Analytical methods}


Chemical oxygen demand (COD) of the collected samples was measured using closed reflux method [10]in a temperature controlled COD digester (HACH,USA).Measurement of phenol wasperformed by 4aminoantipyrine method [10].All other parameters weremeasured as described in APHA[10]

\subsection{Toxicity Test}

Percentage of toxicity removal was estimated by the Resazurin reduction method [11]. A mixed microbial consortium wasemployed to perform the toxicity test. The percentage toxicity of the before and after treatment of the syntheticwastewater was calculated as given below.

$$
\text { \% Toxicity }=\left[\frac{A-B}{C-B}\right] 1
$$

Where, A denotes theabsorbance of synthetic wastewater (OD at $610 \mathrm{~nm}$ ); Brepresents theOD of the mixed microbial consortia without phenol and $\mathrm{C}$ stands for the OD of the reagent control.

$$
E=1\left[\frac{\% \text { Toxicity }_{i}}{\text { \% } \text { Toxicity }_{f}}\right] 2
$$

Where, E denotes \%of toxicity removal, Toxicityi strands for the $\%$ of toxicity by the raw synthetic wastewater. Toxicityf represents the $\%$ of toxicity remaining after treatment with MCM-41.

\subsection{Synthesisof MCM-41}

The MCM-41 was synthesized as depicted [12]. In $120 \mathrm{ml}$ of water 2.4 gram of cetyltrimethylammonium bromide $(\mathrm{CTAB})$ was dissolved at room temperature with constantly stirring. Then $10.5 \mathrm{ml}$ of NH3solution (25\%) was mixed under continuously stirring at $300 \mathrm{rpm}$ followed by addition of $10.0 \mathrm{ml}$ of tetra-ethyl-ortho silicate followed by stirring for $1 \mathrm{~h}$. The milky slurry solution generated was filtered and washed repeatedly, andthe obtained product was dried at $110^{\circ} \mathrm{C}$ for $24 \mathrm{~h}$ in a hot air oven. The oven dried product was calcinated at $550{ }^{\circ} \mathrm{C}$ for $5 \mathrm{~h}$.

\subsection{Characterization}

The synthesized MCM-41 was characterized by FTIR spectra (Make: Japan, Model JASCO-4100). MCM-41 was analyzed by Powder X-ray diffraction (PXRD) technique (RigakuMiniflex set at $30 \mathrm{kV}$ and $15 \mathrm{~mA}$ ) at a scanning rate of $2 \mathrm{o} / \mathrm{min}$ in steps of 0.01 oin $2 \theta$ range of $1-10 \mathrm{o}$ by using a $\mathrm{Cu} \mathrm{K \alpha}$ radiation Further, Transmission scanning electron micrograph (TEM) of the synthesized MCM-41 was performed by employing a LEO-1430VP electron microscope.

\subsection{Effect of adsorbent dose}

The effect of adsorbent dose was studyed in a $250 \mathrm{ml}$ Erlenmeyer flask by employing $50 \mathrm{~mL}$ of synthetic wastewater and at an optimum $\mathrm{pH}$ of 5.0 The adsorbent doses of each Erlenmeyer flask was varied in the range of $0.0125-0.125 \mathrm{gm}$. A control flask without any MCM-41 adsorbant was taken to estimate the loss due to volatilization. Under room temperature all the flasks were kept in a rotaory shaker at $100 \mathrm{rpm}$. Sampling was collected at regular interal of time. The contents of the conical flasks were centrifuged at $8000 \mathrm{rpm}$ for 20 minutes follwed by filtered through mollipore 0.45 micron filter and the filtrates were analyzed for residual phenol concentration.

\subsection{Effect of initial phenolic concentration}

Batch mode experiments were carried out in a $250 \mathrm{ml}$ Erlenmeyer flask with optimum amount of adsorbent dose of 2 gml-1 and varying initial phenolic concentration in the range of $150-300 \mathrm{mgl}-1$. The $\mathrm{pH}$ of each flask was maintained at 5 and was kept in a rotaory shaker at $100 \mathrm{rpm}$ in room temperature. Samples were collcted at regular interal of time andcentrifuged at $8000 \mathrm{rpm}$ for $20 \mathrm{~min}$ followed by filtrtaion by milipore $0.45 \mu \mathrm{m}$ membrane filter and used for analysis of residual phenol.

\subsection{Adsorption isotherms}

Adsorption isotherm experiments were carried out in batch shake flask with a adsorbent dose of $2.8 \mathrm{~g} / \mathrm{L}$ at $\mathrm{pH} 5$ and agitation speed of $98 \mathrm{rpm}$ with varying initial phenol concentration[13]. At regular intervals of time samples were collcted and anlyzed for residual phenol concentration. The phenol removal data were fitted to different literature existing isotherm such as; Langmuir, Freundlich and Temkin adsorption isotherms.

\subsection{Adsorption Kinetics}

2.9 a Lagergren's Pseudo First Order Kinetics:In order to predict the mechanism involved in the adsorption process, investigation of batch adsorption kinetics is necessary. Lagergren'spseudo first order kinetic model has been usuallyemployed for prediction of pollutant adsorption asgiven in the equation below[14].

$$
\frac{d q}{d t}=k_{1}\left(q_{e}-q\right)
$$

Where,q denotes amount of pollutant adsorbed $(\mathrm{mg} / \mathrm{g})$ at any time $t$, qe denotes the equilibrium adsorption capacity of MCM-41 (mg/g) and k1 stands for pseudo first order rate constant (h-1). The above equation is simplified as follow:

$$
\ln \left(\frac{q_{e}}{q_{e}-q}\right)=k_{1} t 4
$$

Thus, from above equation the rate constant $\mathrm{k} 1(\mathrm{~h}-1)$ can be estimated from the plot of $\ln (\mathrm{qe} / \mathrm{qe}-\mathrm{q})$ versus time.

2.9 b Pseudo Second Order Kinetics: The pseudo second order kineticsproposed by Ho [15]isshown as follows.

$$
\frac{d q}{d t}=k_{2}\left(q_{e}-q\right)^{2} 5
$$

k2 denotes Pseudo second order rate constant (gmg-1min1), the above Equation (5) can be simplified as follows ;

$$
\frac{t}{q}=\frac{1}{k_{2} q_{e}^{2}}+\frac{1}{q_{e}} t 6
$$


The value of the constants qe (mgg-1) and k2 (gmg-1 h-1) can be estimated from plot between $\mathrm{t} / \mathrm{q}$ versus $\mathrm{t}$. Further, the initial adsorption rate $\mathrm{h}$ at $\mathrm{t} 0$ can be estimated asbelow:

$$
h=k_{2} q_{e}^{2} 7
$$

2.9 c Intraparticle Diffusion Model: The intraparticle diffusion plot has been popularly used to study the mechanisminvolved during the process ofpollutant adsorption. In literature, it was observed that the plot of qt versus t0.5signify multi-linearity, which indicates multiple steps are associated duringtheprocess [16]. The intra-particle diffusion coefficient Kican be expressedas follows:

$$
K_{i}=\frac{q_{t}}{t^{0.5}}+C 8
$$

Where, qt denotes the quantity of phenol adsorption $(\mathrm{mg} / \mathrm{g})$ at time $\mathrm{t}$. Ki stands for intraparticle diffusion rate constant. $\mathrm{C}$ denotes for the thickness of boundary layer. The intra-particle diffusion process is effective when the correlation coefficient obtained by fitting the experimental data to the equation 8 is close to one. The existence linear correlation between $\log$ (\% removal) and log (time) further confirms the occurrence of intraparticle diffusion process [17]. In solid-liquid adsorption process, thetransfer of solute was typically characterized by either external mass transfer or intraparticle diffusion or both.

\section{RESULTS AND DISCUSSION}

\subsection{Characterization MCM-41 nanoparticles}

Characterization of synthesized MCM-41 was carried out by FTIR, XRD and SEM analysis. FTIR spectra of the MCM-41 is shown (figure1).The bending vibration of $\mathrm{HOH}$ caused by deformation vibrations of water molecules is appeared at $1634 \mathrm{~cm}-1$ [18]. The absorption band at 3460 cm-1 indicatesthe stretching mode of water $[19,20]$.Similarly, the asymmetric extension vibration of siloxane groups (-Si-O- $\mathrm{Si}-$ ) is observed at strong band near $1100 \mathrm{~cm}-1$. Further, occurrences of strong peaks at 3460 and $1634 \mathrm{~cm}-1$ clearly indicates surfactant has been completely removed from the calcined MCM-41.The band near2800$4000 \mathrm{~cm}-1$ reveals the presence of hydroxyl groups in the synthesized the MCM-41.

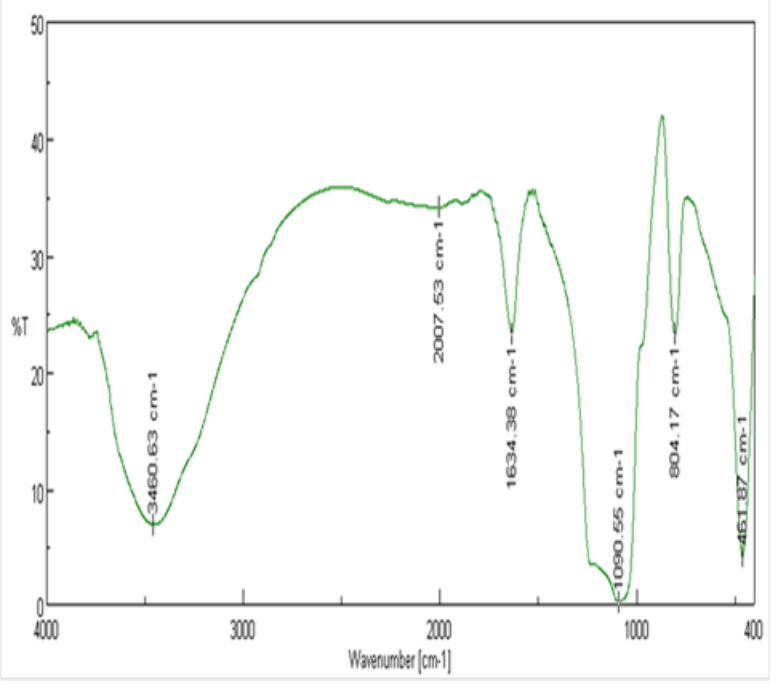

Figure 1.FTIR spectra of the synthesized MCM-41 nanoparticle.
The TEM image of the MCM-41 is given in (Figure2) which reveals the well-ordered hexagonal array of mesoporous structure with pore size varies from 1.5 to $10 \mathrm{~nm}$ in diameter. The occurrence of uniformly distributed homogeneous mesoporous structure facilitates the uses of the MCM-41 as a better adsorbent.

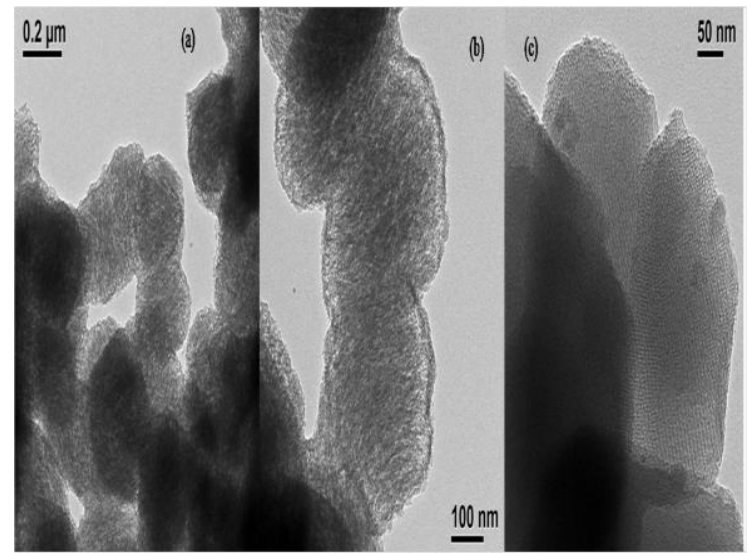

Figure 2.Transmission electron microscopic (TEM) images of the synthesized MCM-41adsorbent.

The of the X-ray diffraction study of the synthesized MCM-41 nanoparticle and details about the crystal structure and phase composition has been discussed in our previous work [21].The presence of hexagonal channel and mesoporosity nature of the synthesized MCM-41 was confirmed by the X-ray diffraction study.

\subsection{Adsorption Isotherms}

\section{2 a Langmuir adsorption isotherm:}

The Langmuir isotherm evaluates the amount of adsorbate adsorbed to form a unimolecular layer on the adsorbent surface. The linear forms of the Langmuir equation $[22,23]$ is given as follows

$$
\text { 1/q_e }=1 /\left(\mathrm{q} \_0 \text { bC_e }\right)+1 / q \_09
$$

Where, q0 represents the maximum amount phenol adsorbed on to MCM-41 for formation a monolayer. Ce denotes concentration of phenol adsorbed at equilibrium condition. The constant term $b$ stands for the binding energy constant and qe is the amount phenol adsorbed per unit mass of MCM-41.The Langmuir adsorption isotherm is plotted between $1 / \mathrm{Ce}$ versus $1 / \mathrm{qe}$ as demonstrated in the Figure 5. The values of $\mathrm{b}$ and $\mathrm{q} 0$ aredetermined from the slope and intercept of the straight line respectively. In the present investigation,the Langmuir constants is estimated as q0 = $200 \mathrm{mg} / \mathrm{gm}$ and $\mathrm{b}=-0.011$. 


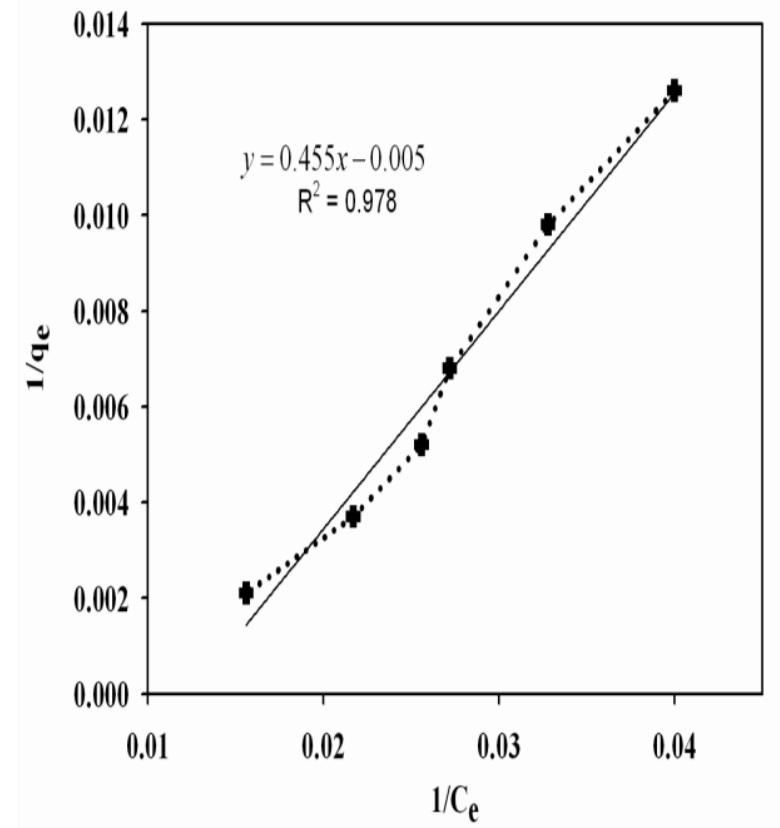

Figure 5.Langmuir adsorption isotherm of synthetic wastewater for phenol removal by MCM-41.

The dimensionless equilibrium parameter $(r)$ is calculated by relating $\mathrm{r}$ with $\mathrm{C} 0$ (initial phenol concentration) and Langmuir constant $b$ as follows [24,25].

$$
r=\frac{1}{\left(1+b C_{0}\right)} 10
$$

Table 1 represents the effect of dimensionless equilibrium parameter ' $r$ ' which reveals the extent of fit of the data obtained in present study to Langmuir isotherm.

Table1. The dimensionless equilibrium parameter ' $r$ ' and its relevance to Langmuir isotherm.

\begin{tabular}{|cccc|}
\hline $\begin{array}{c}\text { 'r' } \\
\text { Value }\end{array}$ & $\begin{array}{c}\text { Condition of } \\
\text { isotherm }\end{array}$ & $\begin{array}{c}\text { Initial } \\
\text { phenol } \\
\end{array}$ & $\begin{array}{c}\mathrm{r} \\
\left(\mathrm{C}_{0}\right) \\
(\mathrm{mg} / \mathrm{L})\end{array}$ \\
\hline $\mathrm{r}>1$ & Unfavorable & 100 & $1 /\left(1+\mathrm{bC}_{\mathrm{o}}\right)$ \\
$\mathrm{r}=1$ & Linear & 150 & 1.54 \\
$0<\mathrm{r}<1$ & Favorable & 200 & 0.83 \\
$\mathrm{r}=0$ & Irreversible & 250 & 0.571 \\
& & 300 & 0.434 \\
& & &
\end{tabular}

The values of the ' $r$ ' indicate that, the adsorption process is unfavorable to fit with Langmuir isotherm at initial phenol concentration below150 mgl-1. On the other hand, when phenol concentration is more than $182 \mathrm{mgl}-1$ the indicates the experimentaldata'sis fitted Langmuir isotherm more precisely

\section{$3.2 b$ Freundlich adsorption isotherm:}

In Freundlich isotherm the adsorption process is regulates by theheterogeneous surface energy.
The linear transformation of Freundlich isothermisgiven as follows:

$$
\log q_{e}=\log K_{f}+\frac{1}{n} \log C_{e} 11
$$

Where, qe represents the adsorption capacity $(\mathrm{mg} / \mathrm{g}), \mathrm{Ce}$ (mgl-1) stands for the equilibrium concentration of adsorbate. The constant terms ' $\mathrm{Kf}$ and $\mathrm{n}$ signify adsorption capacity and adsorption intensityof the adsorbent respectively.

The Freundlich isotherm is plotted between $\log \mathrm{Ce}$ against $\log$ qe as shown in Figure 6, which clearly designatesthat, the experimental data are fitted well to the Freundlich isotherm i.e. nearly a straight line with correlation coefficient of (R2) 0.985.The value of correlation coefficient clearly reveals that Langmuir isotherm fits the experimental data better than that of Freundlich isotherm. In the present study the values of $1 / \mathrm{n}$ i.e. $1.981(\leq 1)$ indicates unfavorable nature of the Freundlich isotherm for phenol removal by synthesized adsorbent.

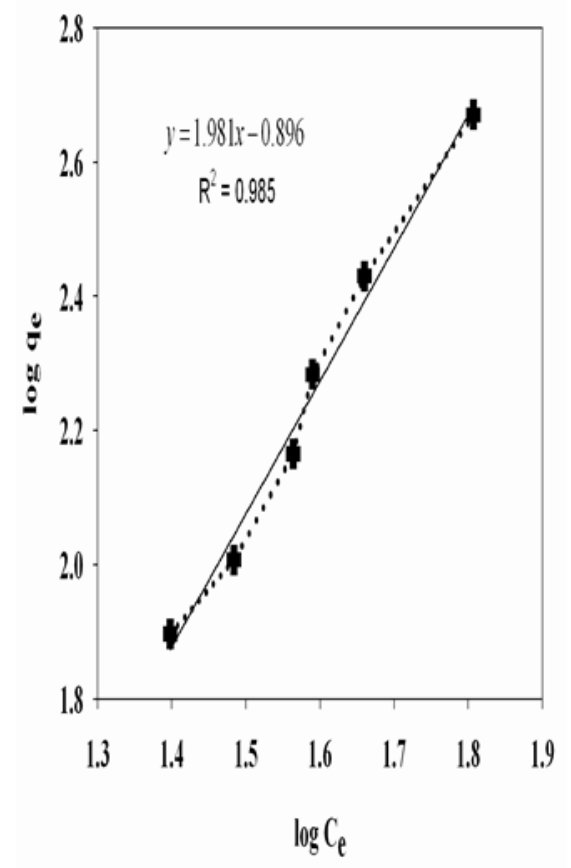

Figure 6.Freundlich adsorption isotherms for phenol adsorption from synthetic wastewater by MCM-41.

The value of Kf (Freundlich constant) reveals affinity of the phenol adsorption on to MCM-41as well as reflects the numbers of sportive sites [26]. In general, the Freundlich constant ' $n$ ' reveals the mutual interaction among the speciesadsorbed on to the adsorbent. For instance: the forces within the surface layers are attractive in nature when ' $n$ ' is more than unity, whereas it is 'repulsive when ' $n$ ' is less than unity [27]. In the present investigation, the experimental value of ' $n$ ' is less than one $1(0.505)$ as calculated from the Freunlich isotherm, which clearly indicates the existence of repulsive forces between the adsorbed species. Therefore, it is clearly understood that 
experimental data did not follow Freundlich adsorption isotherm. Since the values of $1 / \mathrm{n}$ arecalculated as 0.5 therefore it is well understood that intraparticle diffusion found to be the rate-limiting step in the phenol adsorption process by the MCM-41. It could be concluded that, the intraparticle diffusion is sufficiently high due to higher value of $1 / \mathrm{n}$, thus intraparticular diffusion is not the rate limiting step as revealed by the values of $1 / n$. The $1 / n$ value reveals formation of weak bond between phenol and MCM41 adsorbent as compared to polycinnamamide thorium (iv) phosphate viz. week vanderwal force [28]. Further the estimated Kf value of 9.1 is relatively low than that of many literatures reported values further confirmed that, Freundlich isotherm did not fit well to the experimental data.

\section{2 c Dubinin-Radushkevich isotherm:}

In general, mechanism of adsorption cannot be interpreted by Freundlich and Langmuir adsorption isotherm constant. Therefore, in the present study Dubinin-Radushkevich(D-R) isotherm has been appliedto understand the adsorption mechanism[29]. The non linear form of D-R isotherm equation is shown in equation 12. The equation 12 was further simplified to linear form as shown in equation 13.

$$
\begin{aligned}
& \ln q_{e}=\ln q_{m}-K \varepsilon^{2} 12 \\
& \varepsilon^{2}=R T \ln \left(1+\frac{1}{C_{e}}\right)_{13}
\end{aligned}
$$

Where $\varepsilon$ is polanyi potential, qe stands for the adsorption capacity, $\mathrm{qm}$ is the theoretical adsorption capacity, $\mathrm{K}$ is Dubinin-Radushkevich constant related to adsorption energy, $\mathrm{Ce}$ is the concentration ofphenol at equilibrium is the universal gas constant.(Figure7) presented the plot of lnqe versus $\square 2$ for removal of phenol by the MCM-41, whichis found to be almost linear with regression coefficient (R2) of 0.987 . The intercept and slope of the plot D-R isotherm plot represents the values of $\mathrm{qm}$ and $\mathrm{K}$ constants respectively i.e. slope $=$ zero $(0)$ and intercept $=4.861$ as illustrated in the (Figure 7). In the present studythe $\mathrm{K}$ value is found to be zero (0) whereas, qm is $496 \mathrm{~mol} 2 \mathrm{~kJ}-2$.

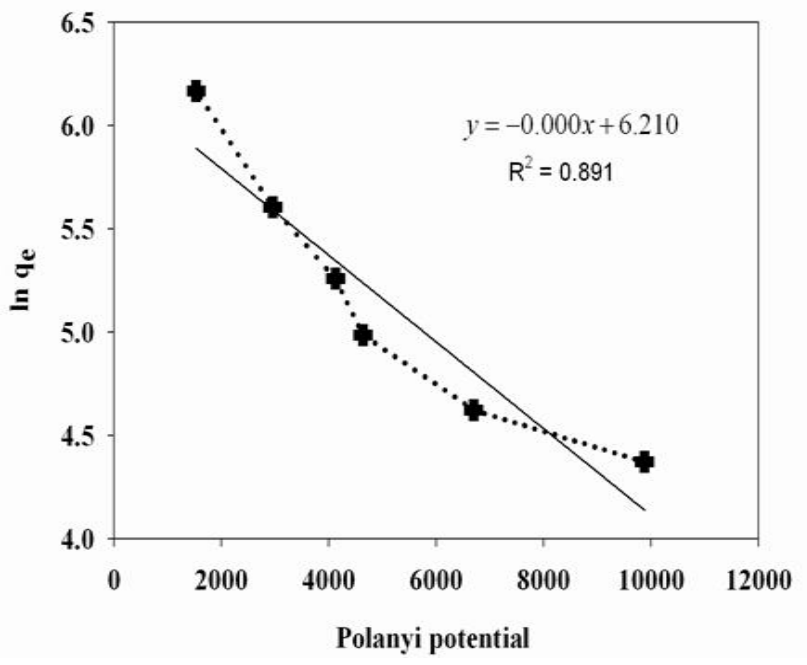

Figure 7.Dubinin-Radushkevich isotherm of synthetic wastewater for phenol removal by MCM-41.

\section{2dTemkin adsorption isotherm:}

In Temkin isotherm the adsorption energy declines linearly with surface coverage of the adsorbent, whereas, in Freundlich equation it varies inlogarithmic form. The Temkin isotherm can be expressed as follows: [30].

$$
q_{e}=\left(\frac{R T}{b}\right) \ln \left(A C_{e}\right) 14
$$

The linear transformation of Temkin equation is shown as follows:

$$
q_{e}=B \ln A+B \ln C_{e} 15
$$

Where $\mathrm{B}=\mathrm{RT} / \mathrm{b}$ denotes the molecular interaction parameter, qe is the adsorption capacity of the MCM41(mgg-1) and Ce (mgl-1) denotes unadsorbed phenol concentration at equilibrium conditions. The equilibrium constant is denoted by $\mathrm{A}$. $\mathrm{R}$ denotes for the universal gas constant (8.314 J mol-1K-1) and $\mathrm{T}$ represents the absolute temperature. The Temkin constants $\mathrm{b}$ is associated with the heat of sorption [31].

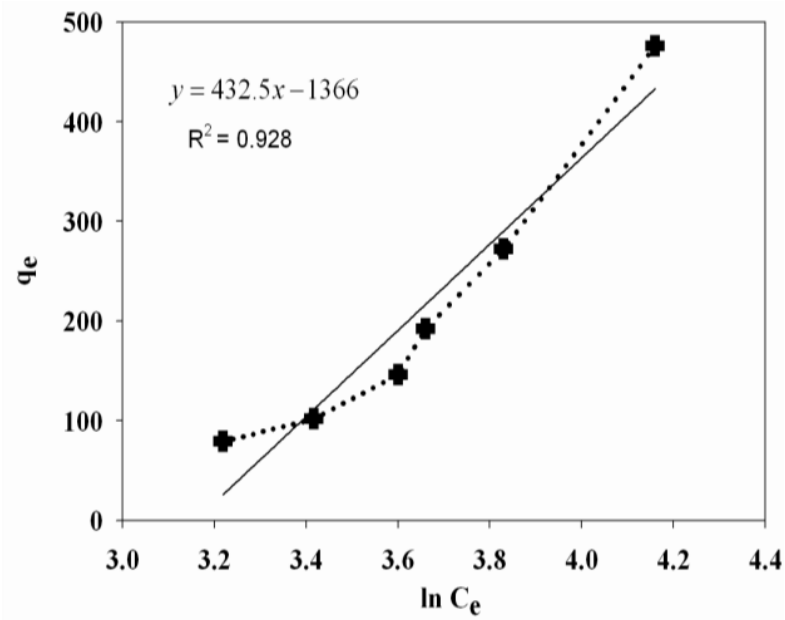

Figure 8.Temkin isotherm of synthetic wastewater for phenol removal by MCM-41.

Temkin isotherm associated with the molecular interactions among the absorbed pollutant(phenol) and adsorbent surface (MCM-41) and the degree of heterogeneity of the adsorbent surface [32]. A plot of $\operatorname{lnCe}$ versus qe is presented in the Figure 8 for phenol adsorption onto the synthesized MCM-41. The slope of the Tremkin isotherm represents, the molecular interaction parameter (B) and is calculated to be 432.5 as shownin Figure8. The values of Tremkin isotherm constant $\mathrm{A}$ and $\mathrm{b}$ are estimated from the intercept and slope of the plot respectively. The values of $A$ and $b$ areestimated to be 23.38 and 5.86 respectively. The calculated interaction parameter B (432.5) is found to be significantly higher when compared with the ' $\mathrm{B}$ ' values for polycinnamamide thorium (iv) polyacrylamide thorium (iv) phosphate (7.0) and phosphate (8.18) which strongly revealing stronger molecular interactions with the adsorbent and hence more phenol are adsorbed on the surface of the MCM-41. This may be due to presence of higher surface area of the mesoporousMCM4ladsorbent. Further, calculated the 'b' value of MCM-41

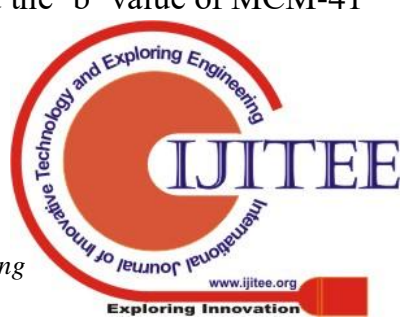


is(5.86), considerably lower than that of many literature reported value i.e. 302,352 , for polycinnamide thorium (iv) phosphate and polyacrylamide thorium (iv) phosphate. This clearly reveals that the heat of sorption during the adsorption of phenol by the MCM-41 is significantly low. The higher coefficient of determination (R2) of 0.928 revealsthat the experimentaldata's are significantly satisfied the Temkin adsorption isotherm.

\subsection{Adsorption Kinetics}

The experimental data's are fitted very wellto pseudo first order and pseudo second order kinetics models as shown in Figures 9 (a,b)and Figure 10 respectively. Table 2 represents the estimated the values of the rateconstants from the linear fitted pseudo first order and pseudo second order models together withthe values of regression the coefficients. From the Table 2 it is clearly examined that the linear correlation coefficients values are significantly high i.e. 0.965 and 0.937 which, reveals that the experimental data are very good fitted with pseudo first order modelat both the phenol concentration tested in the study. However, pseudo second order model did not fit the experimental data with lower correlation coefficient value $(\mathrm{R} 2=0.239)$.

Table 2. The values of pseudo first order and pseudo second order rate constants for phenol adsorption on to MCM-41.

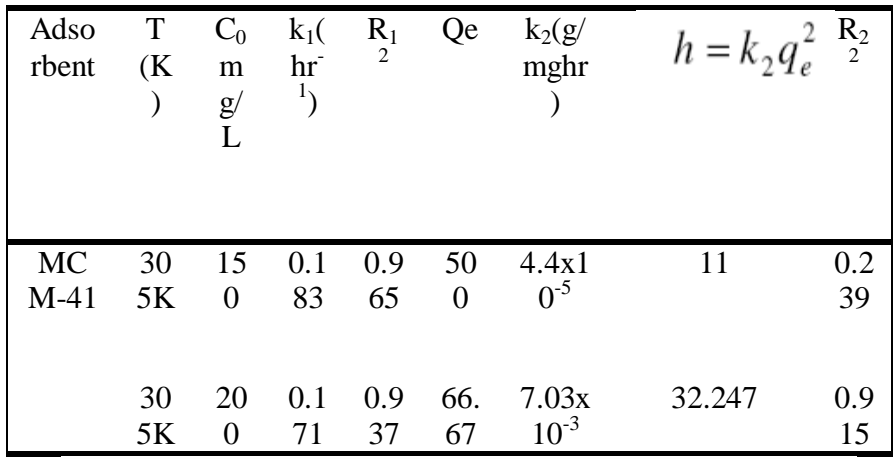

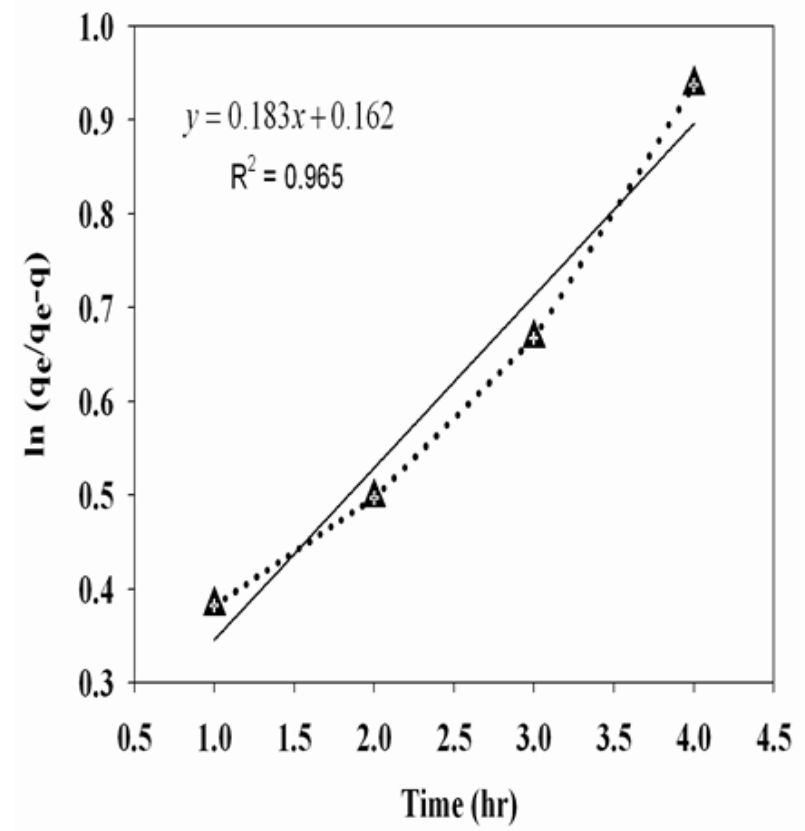

Figure 9 (a)Pseudo first order kinetic plots of phenol adsorption at $150 \mathrm{mgl}-1$ by MCM-41 at 305K.

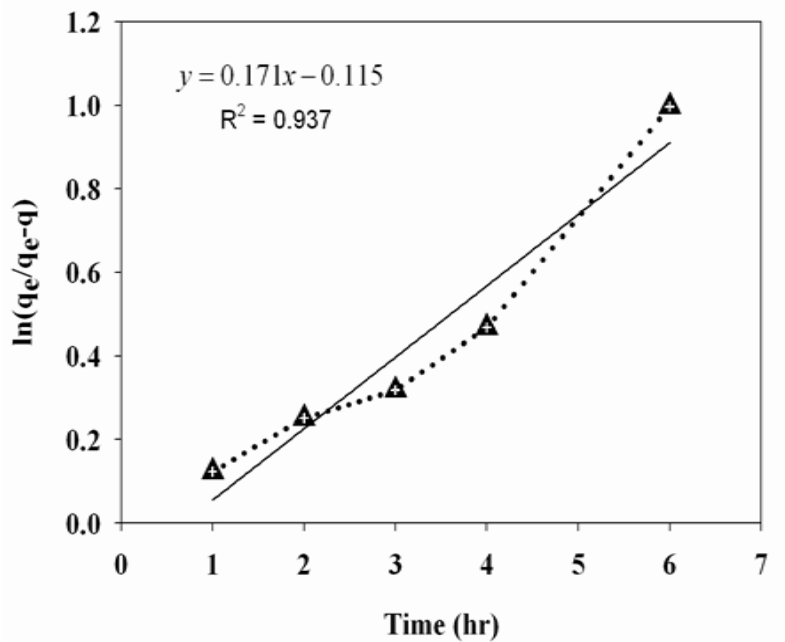

Figure 9(b). Pseudo first order kinetic plots of phenol adsorption at $200 \mathrm{mg} / \mathrm{L}$ by MCM-41 at 305K.

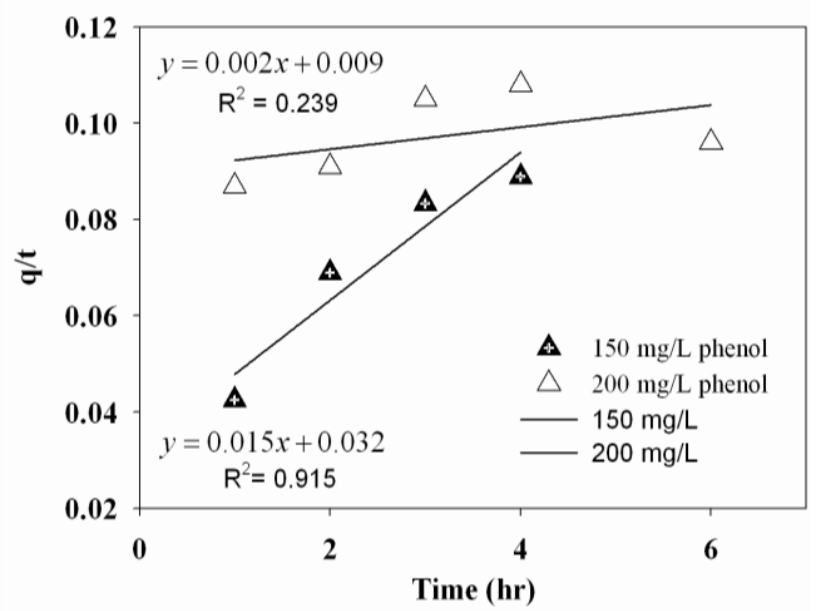

Figure 10. Pseudo second order kinetic plots of phenol adsorption at $150 \mathrm{mgl}-1$ and $200 \mathrm{mgl}-1$ by MCM-41 at $305 K$.

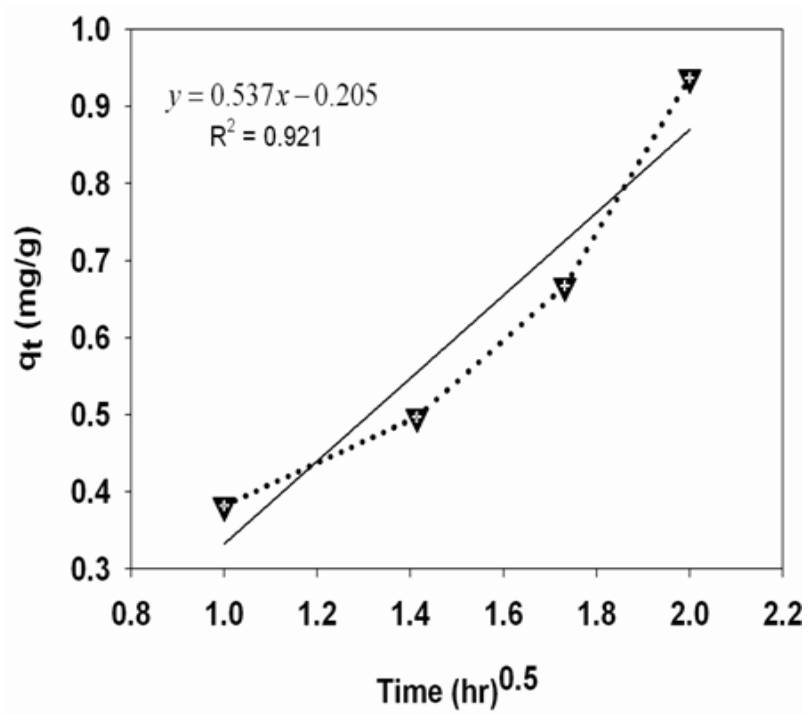

Figure 11 (a). Intraparticle kinetic plots of phenol adsorption at $150 \mathrm{mg} / \mathrm{L}$ by MCM-41 at 305K. 


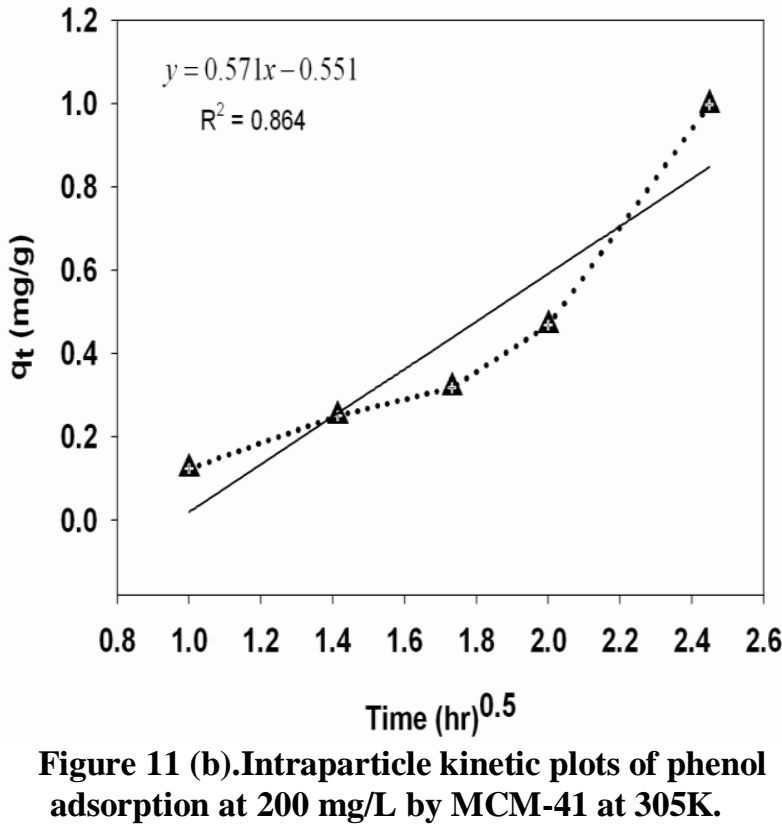

\subsection{Intraparticle Diffusion}

The intraparticle diffusion coefficients for phenol adsorption onto MCM-41 are deliberated

from the slope of the plot between square root of time (min 0.5) versus amount of phenol adsorbed (mgg-1). In literature, manyresearchers reported that, the plot between qt versus t 0.5 correspond to multiple linearity, which signify the involvement of multiple steps during the pollutantadsorption process $[14,16]$. Figures11 (a,b) demonstrated the plot between qt versus t 0.5 for adsorption of phenol at $150 \mathrm{mgl}-1$ and $200 \mathrm{mgl}-1$ respectively onto the MCM-41 nano-adsorbent. From these Figures, it is understood that, at all initial concentrations of phenol, the process of adsorption occurred in two phases i.e.an initial linear portion that completed with a smooth curve after that second linear portion. In the intraparticle diffusion plot the appearance of two phases reveals that the phenol adsorption on to MCM-41 progress by surface adsorption followed by intraparticle diffusion. The first curved portions of the plot signify theeffect of boundary layer whereas, intra-particle or pore diffusion process of phenol adsorption on to MCM-41 is represents by the second linear portion of the curve. The intraparticle diffusion parameter $\mathrm{Ki}(\mathrm{mg} / \mathrm{g} \mathrm{hrO} .5)$ can be estimated from the slope of the second linear portion of the curve whereas the effect of boundary layer can be evaluated by it's, intercept. Greater value of the intercept as shown in the Figures11 $(\mathrm{a}, \mathrm{b})$, higher the surface adsorption process in the rate limiting step [33]. In the present study, intraparticle diffusion parameter Kifor phenol adsorption on to MCM 41 is calculated to be 0.744 and $0.970 \mathrm{mg}-1 \mathrm{~h}-10.5$ at 150mgl-1and $200 \mathrm{mgl}-1$ of phenol respectively. Whereas, boundary layer parameter i.e. the intercept of the linear portion of the curve is estimated to be 0.576 and 1.406 at $150 \mathrm{mgl}-1$ and $200 \mathrm{mgl}-1$ of phenol respectively on to MCM-41. In general,the rate of adsorption governs by the slowest stepi.e. either pore diffusion or film diffusion. In the earlier stages the adsorption of phenol onto MCM-41 might be regulated owing to film diffusion and when the phenol is loading on to the MCM-41 increases the adsorption process might be regulated because ofintraparticle diffusion [33].

\section{CONCLUSION}

The FTIR spectrum of the synthesized MCM-41 hasbeen confirmed the presence of functional groups such as hydrogen bonded $\mathrm{OH}$ groups, silanol groups ( $\mathrm{Si}-\mathrm{OH})$. Similarly TEM micrographs reveals hexagonal mesoporous structure of the MCM-41, and which is further confirmed by the appearance of a strong diffraction peak at 2.30 (100 plane). The experimental data were very well fitted to the Langmuir and Temkin adsorption isotherms with a very high correlation coefficient value of greater than 0.9 . . The lower value of heat of sorption indicates the adsorption process is favorable. For enhancing its adsorption efficiency the sorption kinetics of phenol onto MCM-41 could be represented by the pseudo-second-order kinetic model. The phenol adsorptionprocess is improved due the presence the mesoporous structure of MCM-41 which facilitates higher molecular interactions with the adsorbent. Further, the phenol adsorption on to MCM-41 is well described by a two-stage diffusion model. Therefore, the present investigation reveals that MCM-41 proved to be potential adsorbent for the removal of phenolic pollutants from industrial wastewaters.

\section{ACKNOWLEDGEMENTS}

The authors acknowledge the financial support received from the Department of Biotechnology Government of India, New Delhi for executionof this research work.

\section{REFERENCES}

1. Sahoo N.K and Panigrahy N 2018 Environ Process.2 287

2. Tsai S.Y and Juang R.S 2006 J. Hazard. Mater.138 125

3. Bai J, Wen J.P, Li H.M and Jiang Y 2007 Proc. Biochem. 42510

4. Trapido M and Kallas J 2000 Environ. Technol. 21799

5. Sprenger C, Lorenzen G and Pekdeger A 2008 Occurrence and fate of microbial pathogens and organic trace compounds at riverbank filtration sites in Delhi, India., TECHNEAU.

6. Khan N.A, Hasan Z and Jhung S.H 2013 J. Hazard. Mater.244444

7. Chaliha S, Bhattacharyya K.G and Paul P 2008 Clean Soil Air Water.36488

8. Zanjanchi M.A, Sajjadi H, Arvand M, Khah A.M and Choobar B.G 2011 Clean-Soil Air Water.39 1007

9. CaoJ ,Wu Y, Jin Y, Yilihan P and Huang W $2014 \mathrm{~J}$ Taiwan-Inst-Chem-E. 45860

10. APHA 2005 Standard Methods for the Examination of Water and Wastewater. 21 Washington DC

11. Sahoo N.K, Pakshirajan K and Ghosh P.K 2011 J. Hazard. Mater.190 729

12. Parida K, Mishra K.G and Dash S.K 2012 J. Hazard. Mater.241395

13. Pattanaik P, Panigrahi N, Mishra J, Sahoo N.K, Dash B.P and Rath D 2018 J. Hazard. Toxic Radioact.22 2

14. Sivaraj R, Namasivayam C and Kadirvelu K 2001 WasteManage. 21105

15. Ho Y.S 2003 WaterRes.37 2323

16. Sun Q and Yang L 2003 Water Res.37 1535

17. Kannan K and Sundaram M. M 2001 Dyes Pig.5125 
18. Pavia, D ,Lampman G.M and Kriz G.S 2001 Introduction to spectroscopy, Harcourt College Publisher,USA.

19. Hu Y, He Y, Wang X and We C 2014 Appl. Surf. Sci. 311825

20. Parvulescu V and Su B.L 2001 Catal. Today. 69315

21. Naidu D, Panigrahi N, Mishra J and Sahoo N.K 2018 Int. J. Nano and Biomat.7 124

22. Das N, Pattanaik P and DasR 2005 J. Colloid. Inter. Sci.292 1

23. Mesina PV and Schuiz PC 2006 J.Colloid.Interface Sci. 299305

24. Moufliha M, Akila A and Sebtib S 2005 J. Haz. Mat. B 119183

25. Singh K.K, Talat M and Hasan SH 2006 Bioresour. Technol. 972124

26. Rao P.S and Bhole AG 2001 J. Ind. Water work assoc.99 100

27. Jaya R, Vivekanandan S and Lakshmi S 2010a Ind.J. Che. 40115

28. Kannan N and Vanangamudi A 1991 Ind.J. Environ. Protec. 18683

29. Eren E and Afsin B 2008 Dyes Pig. 76220

30. Wang XS and Qin Y 2005 Proc. Biochem. 40677

31. Akkaya G and Ozer A ,2005. Proc. Biochem. 403559

32. El-Shafei AA, Moussa MNH and El-Far AA 2001 Materials Chem. Phy. 70175

33. Vadivelan V and Kumar K.V 2005 J. Colloid Int Sci.286 90. 